\title{
The Estimated Evacuation Time for the Emergency Planning Zone of the Kori Nuclear Site, with a Focus on the Precautionary Action Zone
}

\author{
Janghee Lee ${ }^{1,2}$, Jae Jun Jeong ${ }^{1, *}$, Wonki Shin ${ }^{1}$, Eunyoung Song ${ }^{2}$, Cheolwoo $\mathrm{Cho}^{2}$ \\ ${ }^{1}$ School of Mechanical Engineering, Pusan National University, Busan; ${ }^{2}$ Division of Nuclear Safety, Busan Metropolitan City, Busan, Korea
}

\section{Original Research}

Received December 14, 2015

Revision April 28, 2016

Accepted May 2, 2016

Corresponding author: Jae Jun Jeong

School of Mechanical Engineering, Pusan National University, 2, Busandaehak-ro 63 beon-gil, Geumjeong-gu, Busan 46241, Korea

Tel: +82-51-510-2455

E-mail: jjjeong@pusan.ac.kr

This is an Open-Access article distributed under the terms of the Creative Commons Attribution NonCommercial License (http://creativecommons.org/ licenses/by-nc/4.0) which permits unrestricted noncommercial use, distribution, and reproduction in any medium, provided the original work is properly cited.

Copyright $\odot$ 2016 The Korean Association for Radiation Protection

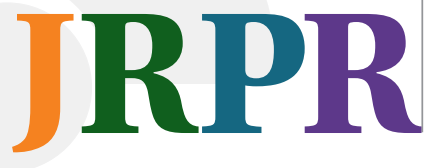

Background: The emergency planning zone (EPZ) of the city of Busan is divided into the precautionary actions zone (PAZ) and the urgent protective action planning zone; which have a $5-\mathrm{km}$ radius and a $20-\mathrm{km}$ to $21-\mathrm{km}$ radius from the nuclear power plant site, respectively. In this study, we assumed that a severe accident occurred at Shin-Kori nuclear unit 3 and evaluated the dispersion speed of radiological material at each distance at various wind speeds, and estimated the effective dose equivalent and the evacuation time of PAZ residents with the goal of supporting off-site emergency action planning for the nuclear site.

Materials and Methods: The total effective dose equivalent, which shows the effect of released radioactive materials on the residents, was evaluated using the RASCAL 4.2 program. In addition, a survey of 1,036 residents was performed using a standardized questionnaire, and the resident evacuation time according to road and distance was analyzed using the VISSIM 6.0 program.

Results and Discussion: According to the results obtained using the VISSIM and RASCAL programs, it would take approximately 80 to 252.2 minutes for permanent residents to move out of the PAZ boundary, 40 to 197.2 minutes for students, 60 to 232.2 minutes for the infirm, such as elderly people and those in a nursing home or hospital, and 30 to 182.2 minutes for those temporarily within the area. Consequently, in the event of any delay in the evacuation, it is estimated that the residents would be exposed to up to $10 \mathrm{mSv} \cdot \mathrm{h}^{-1}$ of radiation at the Exclusion Area Boundaries (EAB) boundary and $4-6 \mathrm{mSv} \cdot \mathrm{h}^{-1}$ at the PAZ boundary.

Conclusion: It was shown that the evacuation time for the residents is adequate in light of the time lapse from the initial moment of a severe accident to the radiation release. However, in order to minimize the evacuation time, it is necessary to maintain a system of close collaboration to avoid traffic congestion and spontaneous evacuation attempts.

Keywords: Emergency planning zone, Precautionary action zone, Urgent protective action planning zone, Severe accident, Total effective dose, Estimated evacuation time

\section{Introduction}

The International Atomic Energy Agency (IAEA) has set general intervention levels and operational intervention levels based on the impact assessment of the Chernobyl disaster. The organization published safety requirements and guidelines based on a classification of emergencies, re-defining the scope and operational concepts involved in establishing emergency plans for different threats. The IAEA has recommended the 
use of these guidelines by its member states $[1,2]$.

Later, based on the lessons learned from the Fukushima Daiichi nuclear disaster, the IAEA revised its radiological emergency planning zones and re-established its operational concepts in the IAEA Emergency preparedness and response-Nuclear power plant (EPR-NPP), which includes additional recommendations on distance limits for consuming vegetables, protecting drinking water and the feed for grazing animals, highlighting the importance of environmental radiation monitoring, setting operational intervention levels to apply in the event of radiation exposure, and establishing concrete time targets for emergency responses on an hourby-hour basis after the occurrence of an accident [3].

As part of the follow-up measures after the Fukushima Daiichi nuclear disaster, Korea classified emergency planning zones (EPZs) into precautionary action zones (PAZs) and urgent protective action planning zones (UPZs) based on the IAEA safety requirements and guidelines, and included these changes in the relevant act [4]. According to the Act on Measures for the Protection of Nuclear Facilities, etc. and Prevention of Radiation Disasters and the Notification of the Nuclear Safety and Security Commission No. 2014-8, nuclear power and nuclear business operators are required to establish radiological emergency response measures that incorporate calculations of the evacuation time from the re-established EPZ.

The current radiological emergency plans for the Shin Kori-3 and 4 nuclear power reactor in Korea were developed before the revision of the Act on Measures for the Protection of Nuclear Facilities, etc. and Prevention of Radiation Disasters. The public evacuation time was calculated based on the following methodology. Using a static assignment module of the VISSIM traffic simulation program (PTV Group, Karlsruhe, Germany), we automatically assigned vehicles to each neighborhood along the designated routes to evacuate the EPZ (with a radius of 8-10 km). We then evaluated the public evacuation time after calculating the evacuation preparation time by conducting phone surveys of 250 residents in the EPZ. The public evacuation time refers to the sum of the transfer time to escape the EPZ and the preparation time for evacuation.

In this study, we analyzed the public evacuation time of the expanded EPZ $(21 \mathrm{~km})$ following the enactment of the revised law in May 2015. To that end, we analyzed the EPZ in terms of roads, distance, and evacuee type. Additionally, we investigated the sociobehavioral characteristics of 1,036 resi- dents both in and out of the EPZ at the time of a hypothetical emergency using a self-reported survey based on a standardized questionnaire. In addition, using the dynamic assignment module of VISSIM (PTV Group, Karlsruhe, Germany), we simulated traffic situations similar to the emergency, by neighborhood, school, and places suitable for a brief stay (e.g., beach or shopping mall), based on the origin-destination model. Then we assigned traffic by allocating a time gap in possible evacuation routes usable by individual vehicles in order to evaluate the public evacuation time.

In this study, we aimed to support the provision of timely evacuation measures in order to prevent evacuating residents from being exposed to radiation emitted into the air during their transfer. We predicted evacuation times considering various characteristics of the selected areas, such as climate, road condition, vehicle mobilization, and traffic situation; forecasted a range of accidental situations in emergencies, including problems subsequent to the evacuation; calculated evacuation travel time on various routes using a traffic simulation program based on an analysis of the sociobehavioral traits of the residents in emergency; and developed suggestions for efficient protection measures for each type of evacuee.

\section{Materials and Methods}

\section{Evaluation details and analysis method}

Adopting a conservative approach, we developed a worstpossible-case scenario affecting residents and the environment. In this scenario, a heat-transfer pipe of the steam generator ruptures, accompanied by a power outage both onand off-site in the Shin Kori-3 reactor (which has the largest source term in the Gori Nuclear Power Division). Subsequently, core damage occurs because the main steam safety valve is stuck open and gaseous and particulate iodine is released into the environment. In reality, however, when a rupture occurs in the heat-transfer pipe of the steam generator, the coolant of the primary cooling system leaks into the secondary cooling system. The safety system automatically turns on and infuses water into the primary cooling system, thereby resolving the incident.

Nonetheless, in this scenario, we assumed that the entire safety injection system would be broken. Therefore, the coolant of the primary cooling system would be depleted, exposing fuel rods and damaging the fuel assembly. Additionally, although in reality the main steam safety valve in the steam 
generator in the back of the second cooling system would remove heat from the primary system by repeatedly opening and closing, we assumed that the main steam safety valve would be stuck open, causing radioactive materials to be released to the environment for an entire hour.

According to the safety analysis report of the Shin Kori-3 and 4 facilities, the frequency of damage to the core due to the failure of the entire safety system (involving heat-transfer pipe rupture, failure of safety water injection, and the main steam safety valve being stuck open) is $3.13 \times 10^{-8}$ per year. Such an accident is highly unlikely in actuality, and this is therefore a very conservative scenario.

Under the assumption of a radiological emergency caused by such a major accident, we evaluated the total effective dose estimation (TEDE), which is a parameter describing the dose affecting the public through radioactive materials released by factors including the leakage path of the radioactive source terms and the weather conditions (e.g., summer, night time, rain, fixed temperature, wind), using RASCAL 4.2 (Pacific Northwest National Laboratory, Washington DC, USA) developed by the Nuclear Regulatory Commission
(NRC). We calculated the dispersion speed of the radioactive materials according to wind speed and the TEDE, using data from the annual climatological report (by the Korea Meteorological Administration [KMA] and local agencies) of the Gijang region, Busan.

The public evacuation time was evaluated through an analysis of road conditions within the EPZ and traffic volume at peak times during the day and at night (Traffic Monitoring System, the Korea Ministry of Land, Infrastructure and Transport), using the NRC regulatory guidelines NUREG0654 Appendix 4 [5] and NUREG/CR -7002 [6] as references. For the analysis of the public evacuation time, we applied the dynamic traffic assignment module of VISSIM, a microscopic traffic simulation program developed by the University of Karlsruhe and commercially distributed by PTV Transworld AG since 1993. Based on the origin-destination (O-D) table, we assigned traffic automatically, allowing time gaps for each vehicle and providing balances for the possible evacuation routes in order to simulate and evaluate traffic situations similar to those that would occur in an emergency.

In order to calculate the evacuation preparation time, we

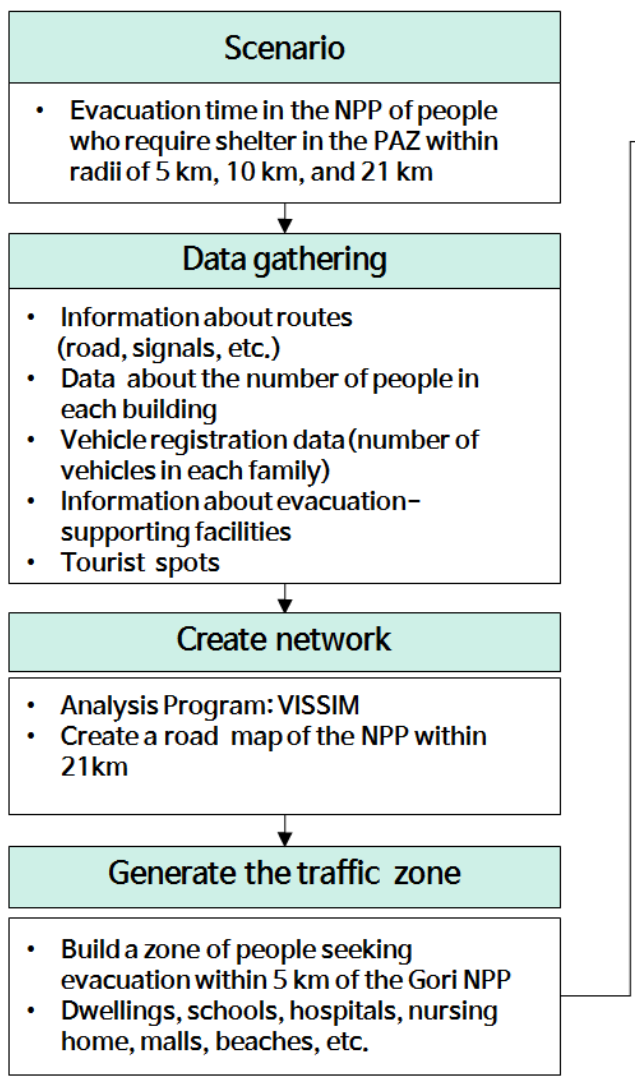

Make an O-D chart for each scenario

- Makean O-D chart taking into account the generated traffic zone, the data gathered regarding people, and the number of vehicle registrations

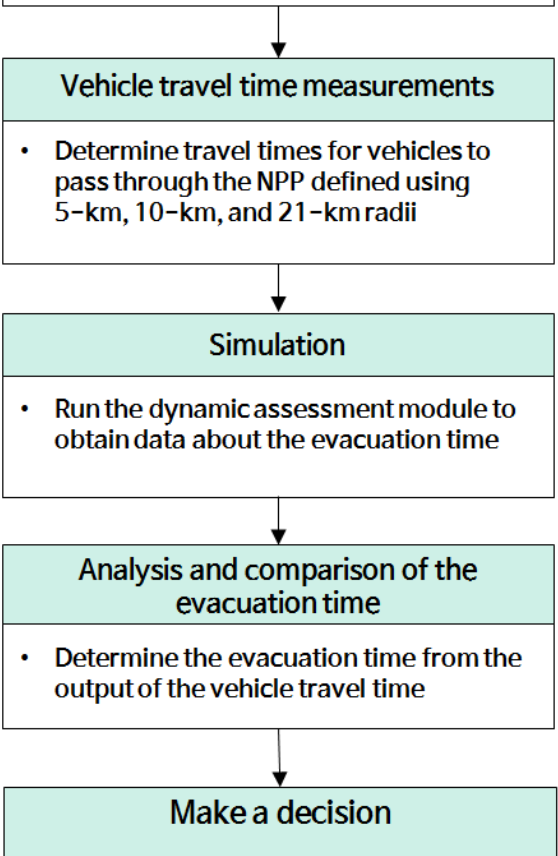

Fig. 1. Flowchart of this study. 
conducted a survey of 1,036 people within and outside of the EPZ and analyzed their sociobehavioral characteristics. We also researched in detail the present condition of nearby structures where people would be located temporarily, such as shopping malls and tourist attractions, general industry infrastructure, and special facilities (e.g., schools, hospitals, and nursing homes), which can influence the evacuation time, and incorporated this information into the study. The flow of the research process (Figure 1) and the spatial range of the study (Figure 2) are based on the EPZ (21 km) of the Busan Metropolitan City.

\section{Results and Discussion}

\section{Evaluation of radiation dispersion and effective dose estimation}

In the event of the previously described major accident, radioactive materials would be released into the environment and may affect extended areas depending on weather conditions. The influence of the exposure on a given street may differ by a dozen times across various weather conditions. The exposure would be greatest in rainy weather for short distances and with a fixed temperature on a summer night for longer distances. Based on KMA data for Busan over the last ten years, we applied weather conditions that commonly affect the area, including north-northeast winwds and rain, which frequently occur during the summer in Busan.
Our analysis based on the above-described scenario and weather conditions (Table 1) found that the total release of radioactive material to the environment would be $4.5 \times 10^{17}$ Bq. Assuming that the whole body would be irradiated without immediate treatment, the range of deterministic effects of acute effects would extend to $2.4 \mathrm{~km}$. Chronic effects are expected to be present at the $100 \mathrm{mSv} \cdot \mathrm{h}^{-1}$ level in a $5 \mathrm{~km}$ radius from the nuclear power plant according to the effective dose established by the general intervention levels defined by the IAEA and the public protection measures proscribed in the relevant law. Regarding the criteria for public protec-

Table 1. Evaluation of the Total Effective Dose Estimation and the Thyroid Dose using RASCAL

\begin{tabular}{lcc}
\hline Distance $(\mathrm{km})$ & TEDE $(\mathrm{Sv})$ & Thyroid $(\mathrm{Sv})$ \\
\hline 0.16 & 35 & 150 \\
0.32 & 16 & 65 \\
0.48 & 9.6 & 33 \\
0.8 & 4.8 & 13 \\
1.13 & 3.1 & 6.7 \\
1.61 & 1.9 & 3.3 \\
2.41 & 1.1 & 1.5 \\
3.22 & 0.7 & 0.79 \\
4.83 & 0.15 & 0.25 \\
6.44 & 0.1 & 0.17 \\
8.05 & $4.6 \times 10^{-2}$ & $8.0 \times 10^{-2}$ \\
11.3 & $1.6 \times 10^{-2}$ & $3.4 \times 10^{-2}$ \\
16.1 & $2.9 \times 10^{-3}$ & $8.2 \times 10^{-3}$ \\
24.1 & $2.6 \times 10^{-5}$ & $1.2 \times 10^{-4}$ \\
\hline
\end{tabular}

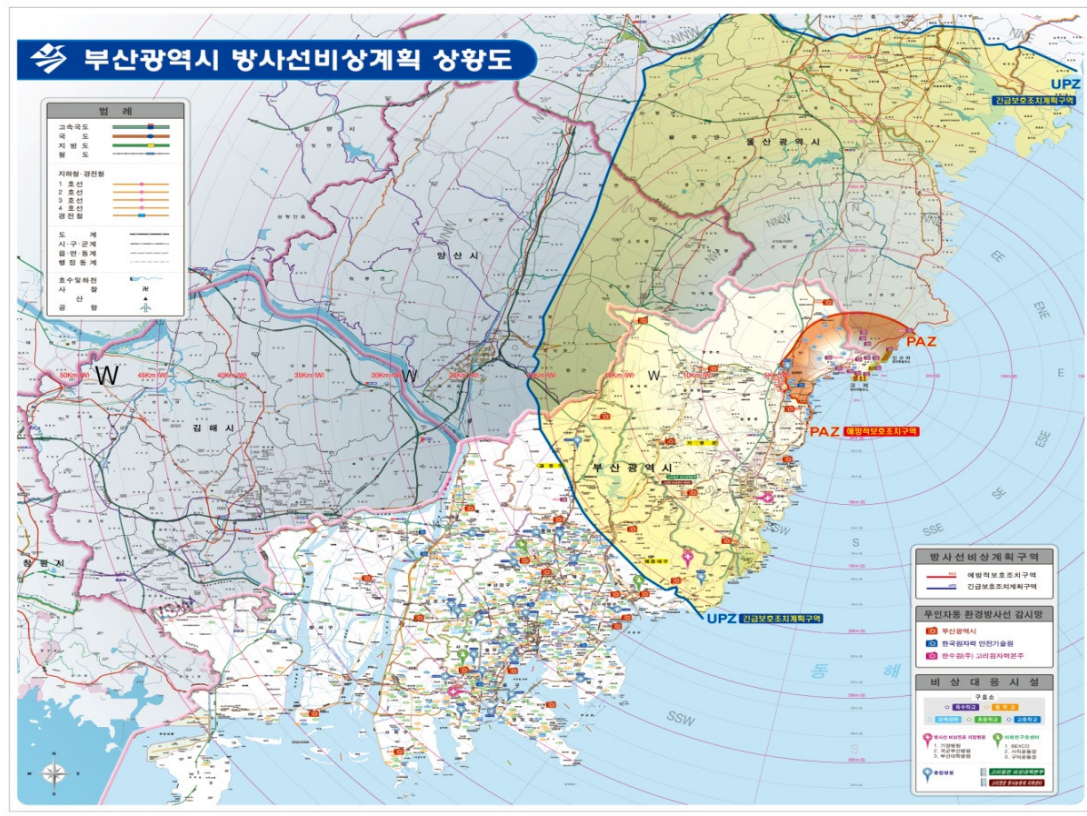

Fig. 2. The emergency planning zone of the city of Busan. 


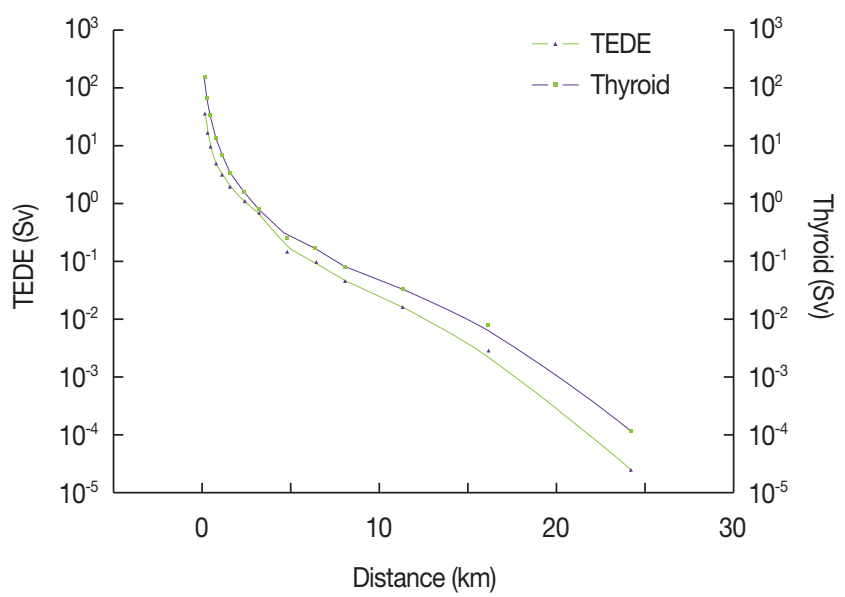

Fig. 3. Predicted exposure doses during severe accidents induced by steam generator tube rupture. TEDE, total effective dose estimation.

tion measures, the distance for which urgent evacuation would be necessary was found to be $7.8 \mathrm{~km}$, the distance for which indoor refuge would be needed was $12.5 \mathrm{~km}$, and the distance for which thyroid protection should be provided was estimated to be $7.5 \mathrm{~km}$ (Figure 3). The thyroid effects were limited to a relatively shorter distance, possibly due to the fact that radioactive iodine was diluted in rain under the assumed weather conditions.

The time for a radioactive cloud released from the main steam safety valve to reach the PAZ boundary varies by weather condition, such as wind direction and speed. Estimated fallout arrival times are strongly dependent on wind velocity, wind direction, atmospheric pressure, and temperature.

As the average annual wind speed in the Gijang area is approximately $2 \mathrm{~m} \cdot \mathrm{s}^{-1}$, based on the KMA annual climatological report, the fallout arrival to the nuclear power plant site boundary was estimated to be around 10 minutes after the release, while 40 minutes would be necessary for fallout to reach the PAZ boundary areas. When the maximum wind velocity of $8 \mathrm{~m} \cdot \mathrm{s}^{-1}$ was applied, the radioactive cloud was projected to reach the PAZ boundary in approximately 10 minutes.

Therefore, in the event of a rupture of the heat-transfer pipe of the steam generator, with a wind speed of $2 \mathrm{~m} \cdot \mathrm{s}^{-1}$ (annual average), fallout would arrive within 1 hour and 40 minutes after the rupture at the area near the nuclear power plant and would reach the PAZ boundary within 2 hours and 10 minutes. These values were estimated using conservative assumptions for the accident and annual weather condi- tions. Also, in reality, the arrival time may be shorter or longer, depending on the extent of the accident, its progression, and weather conditions. Given the geographical characteristics of the Busan region, the time of fallout arrival may be delayed for more than 30 minutes longer than our estimates.

The IAEA technical guidelines establish the following emergency response time objectives [7]: The on-site control team provides a warning within 15 minutes under the emergency warning criteria, and informs off-site emergency services of the warning status as well as provides recommendations for protection measures within 30 minutes. Additionally, the team should inform the local residents of the emergency status of the nuclear power plant and of the protective actions that should be performed within 45 minutes. The recommended urgent protective actions should be carried out within 1 hour.

In contrast, in Korea, On-Site Command Centers for the Prevention of Radioactive Disasters are organized and run by the Nuclear Safety and Security Commission (NSSC) in the event of code-blue emergencies. The off-site emergency measures, including decision-making for resident protection measures, the delivery of recommendations regarding protective measures to the heads of the off-site local governments, warning residents about the emergency, and the delivery of information on protective measures may take longer than assumed in this study. Under the current system, even if we minimize the time for decision-making by the disaster countermeasures council, it will take at least 30 minutes from the occurrence of the accident to the time when the residents are informed.

Therefore, residents in the PAZ are likely to receive the notification to take protective measures approximately $45 \mathrm{~min}$ utes after the accident. In order to avoid deterministic effects, they should escape the PAZ boundaries in approximately 1 to $1 \frac{1 / 2}{2}$ hours. Otherwise, they would suffer from the effects of radiation in proportion to the delay.

\section{Public evacuation time and data analysis}

The major nuclear power states, such as the U.S. and Japan, also use verified VISSIM programs to evaluate public evacuation times. Notably, in the U.S., vehicle demand is estimated based on peak traffic time per season and day/night time in an EPZ of 10 miles $(16 \mathrm{~km})$ for all individual nuclear facilities, as well as incorporating a $20 \%$ occurrence rate of shadow evacuation outside the EPZ, based on detailed regulatory guidelines. The U.S. uses the results of these evalua- 


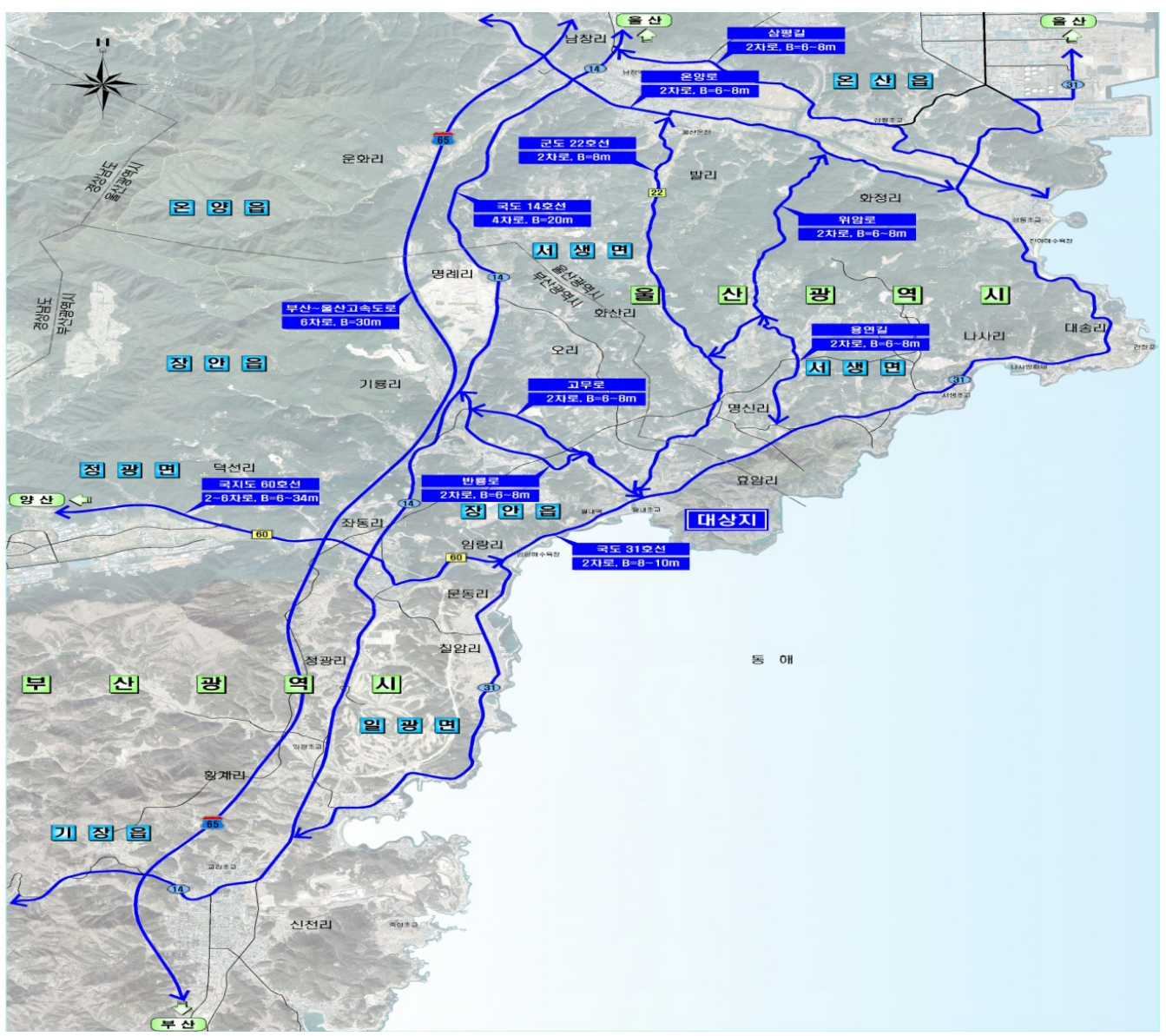

Fig. 4. The current road network (exit routes) near the Kori nuclear site.

tions in selecting proper exit routes and incorporates these findings into off-site emergency plans.

Japan has incorporated its evacuation experience from the Fukushima accident into its evaluation of evacuation times. Currently, 6 patterns and scenarios applying 2 types of evacuation order timing (total evacuation and phased evacuation) are created for each area receiving evacuation orders. Evaluations are performed for daytime and nighttime evacuations separately [8]. In particular, selected local governments within a 30-km radius from the EPZ of each nuclear power plant are evaluated for evacuation times according to the following criteria: the selection of screening spots for each road; limiting evacuation directions according to their processing ability per hour for each location and wind direction; expanding the shadow evacuation rate (to $100 \%$ ); and considering pre-evacuation of the people vulnerable to disasters in places such as hospitals.

We verified that no major differences were present between the evaluation results of the situation simulated in this
Table 2. Total Evacuation Time for Each Exit Route and Distance

\begin{tabular}{lcccccc}
\hline \multirow{2}{*}{ Classification } & \multicolumn{2}{c}{ Minimum time $(\mathrm{min})$} & & \multicolumn{2}{c}{ Maximum time $(\mathrm{min})$} \\
\cline { 2 - 3 } \cline { 5 - 6 } & $5 \mathrm{~km}$ & $21 \mathrm{~km}$ & & $5 \mathrm{~km}$ & $21 \mathrm{~km}$ \\
\hline 65 & 12.61 & 58.05 & & 152.2 & 247.6 \\
Speedway & & & & & \\
14,31 & 10.7 & 30 & & 130.6 & 167.3 \\
Highway & 10.22 & & & 94.3 & \\
60 & 11.26 & 42.73 & & 136.2 & 247.9 \\
Local road & & & & & \\
\hline
\end{tabular}

study (Table 2) in the roadway network around the Kori nuclear power plant (Figure 4) and the preparation time (60120 minutes) and travel time (73-178 minutes) described in the radiological emergency plans for Shin Kori-3 and 4 [9].

One of the notable findings of this study was that the selfreported shadow evacuation rate was greater than $40 \%$, which is significantly higher than the $20 \%$ suggested by the U.S. Such a result demonstrates the unique public sentiment in Korea, as was also illustrated in the aftermath of the 2011 
Fukushima accident and the recent Middle East respiratory syndrome outbreak, in which a series of actions, including school closures, took place without concrete scientific evidence.

Additionally, we found that the evacuation preparation time and the decision-making time were shorter by approximately 10 to 20 minutes for the residents in the EPZ who had undergone radiation disaster preparedness education and training than among their counterparts who did not have such experience. Moreover, 14\% of the former group responded that they would evacuate to designated relief stations in their neighborhood, compared to $3.7 \%$ of the latter group. In order to ensure the prompt evacuation of the PAZ residents in the case of a code-red emergency, emergency plans extending beyond the relief stations should also be established, based on the results of the evacuation time simulation and using cases from advanced countries and the results of prior studies.

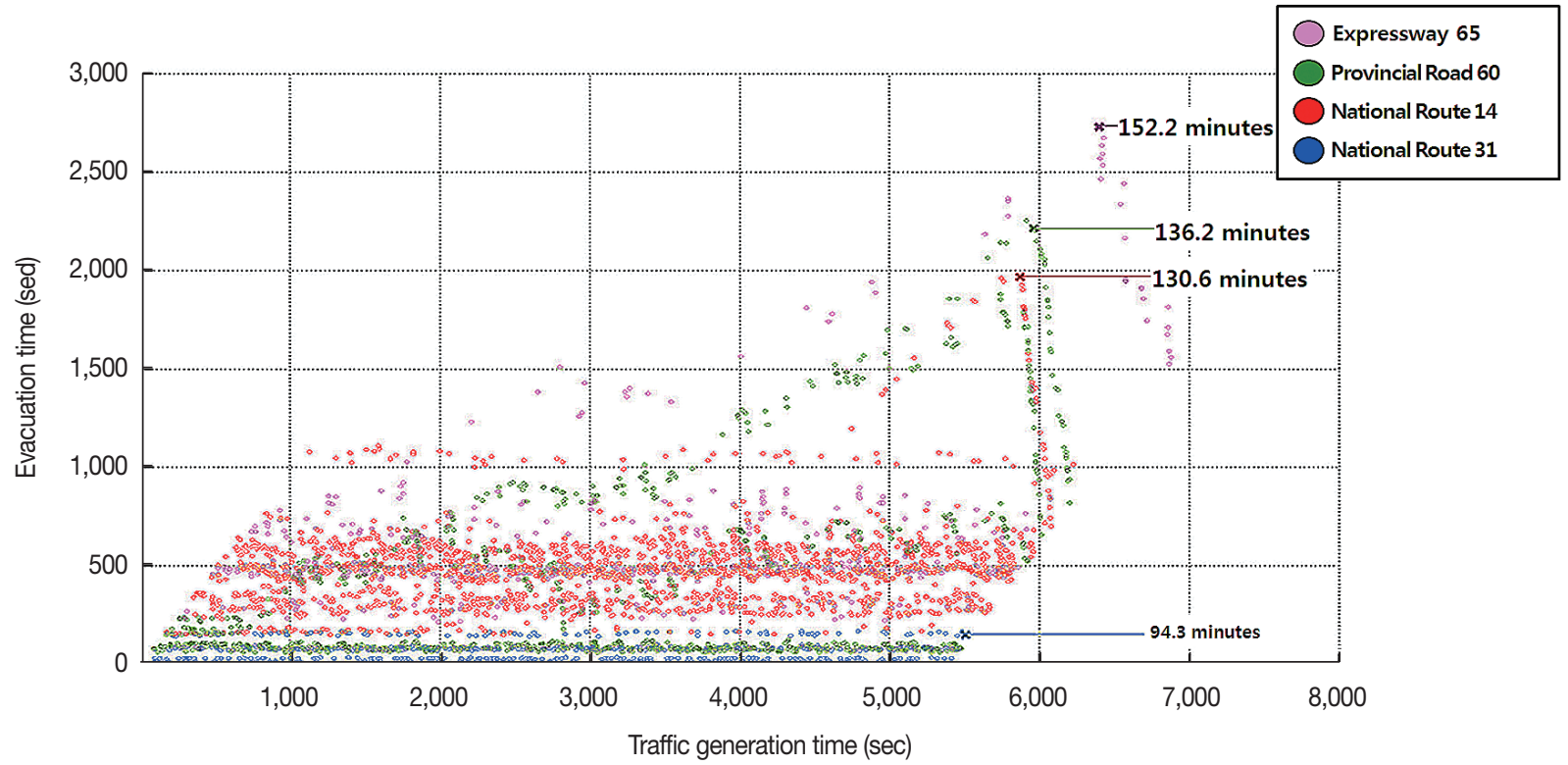

Fig. 5. Estimated 5-km evacuation time by vehicle for each exit route from the Kori site.

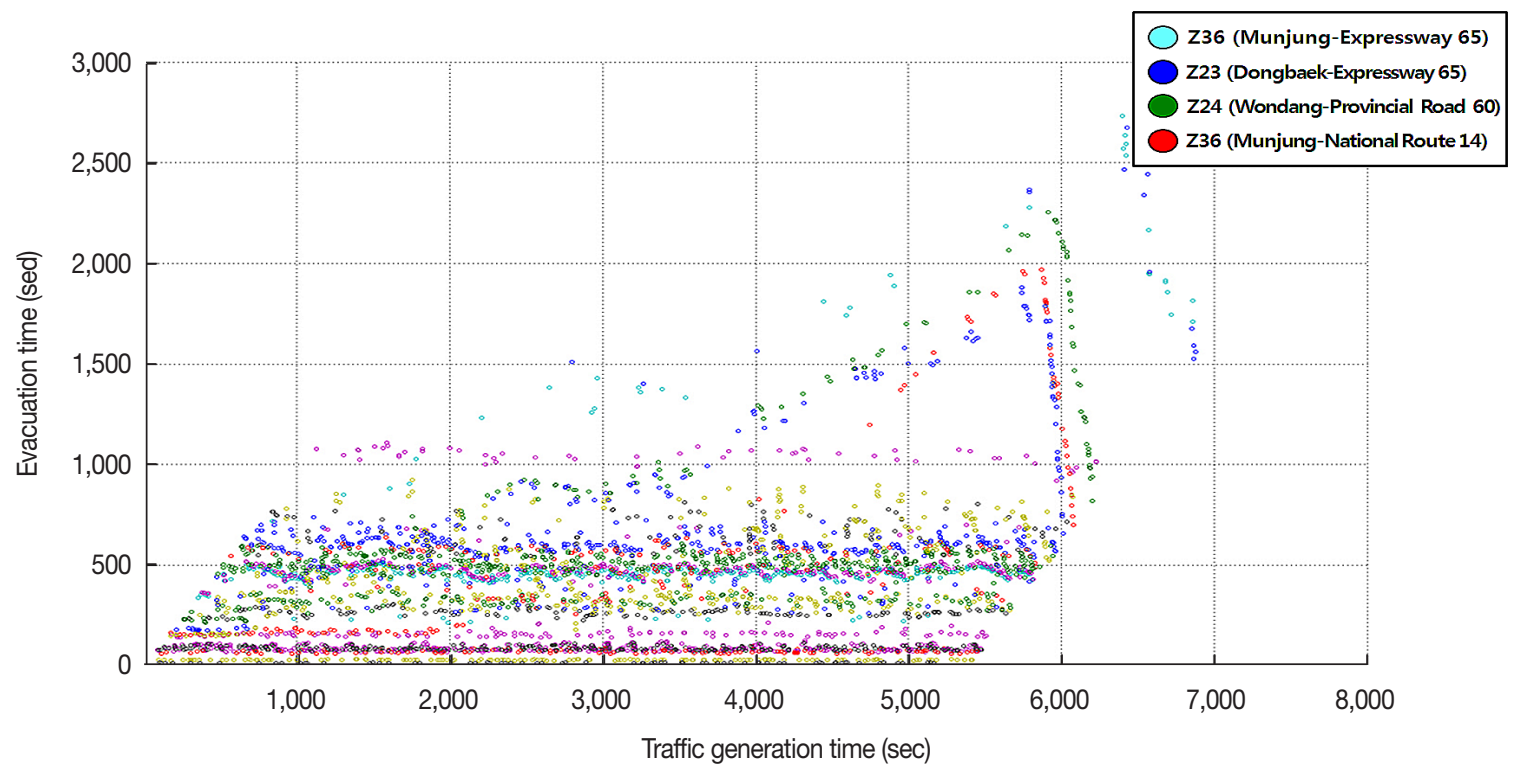

Fig. 6. Bottlenecks within $5 \mathrm{~km}$ from the Kori nuclear site for each origin-destination (O-D) pair. 
1) Time to evacuate to a 5 -km distance

Expressway 65 had the longest time for evacuation (152.2 minutes), while National Route 31 had the shortest time (94.3 minutes), as shown in Figure 5.

For ranges up to $5 \mathrm{~km}$, National Route 31 was found to be the optimal evacuation route. Evacuation times on the other routes were relatively consistent. However, Expressway 65 and Provincial Road 60 were likely to take longer due to traffic delays. Some bottleneck spots occurred in Munjung (Figure 6), and cars in Zone 36 that took Expressway 65 and National Route 14 as well as cars in Zone 24 going from Wondang to Provincial Road 60 took more time. Those zones would require prompt traffic control in the case of an emergency.

The reason why more vehicles used National Route 14 than Expressway 65 appears to be that most cars coming from the areas within $5 \mathrm{~km}$ take National Route 14 to reach Expressway 65 at the $21-\mathrm{km}$ mark.

\section{2) Time to evacuate to a $21-\mathrm{km}$ distance}

As shown in Figure 7, it took the same time to evacuate to 21 km via Provincial Road 60 and Expressway 65 (247.6 minutes and 247.9 minutes, respectively). The shortest time was observed for National Routes 14 and 31 (167.3 minutes).

For Provincial Road 60, a delayed departure time led to an extended delay due to the effects of the traffic generated ear- lier, which resulted in higher average evacuation time with identical distribution patterns for the evacuation times.

Proper traffic distributions for each road and proactive traffic control would be necessary for the bottleneck sections (Figure 8).

National Routes 14 and 31 were found to allow the speediest evacuations. When National Route 31 (currently under construction for expansion) is expanded at the end of 2016, the evacuation time is expected to be further reduced.

\section{Conclusion}

The EPZ defines the area for intensive planning for protective measures such as indoor refuge and evacuation in advance of a radiation leakage accident in nuclear facilities. Notably, residents in the PAZ need to be evacuated proactively in order to ensure that they do not receive any radiation exposure. However, in reality, countless variables may emerge as on-site challenges, as occurred in the Fukushima Daiichi nuclear disaster.

In this paper, we analyzed evacuation times for permanent and transient residents in the PAZ, in the case of a major accident involving the release of radioactive materials from the Kori nuclear power plant. We sought to characterize measures that would be effective in protecting residents from ra-

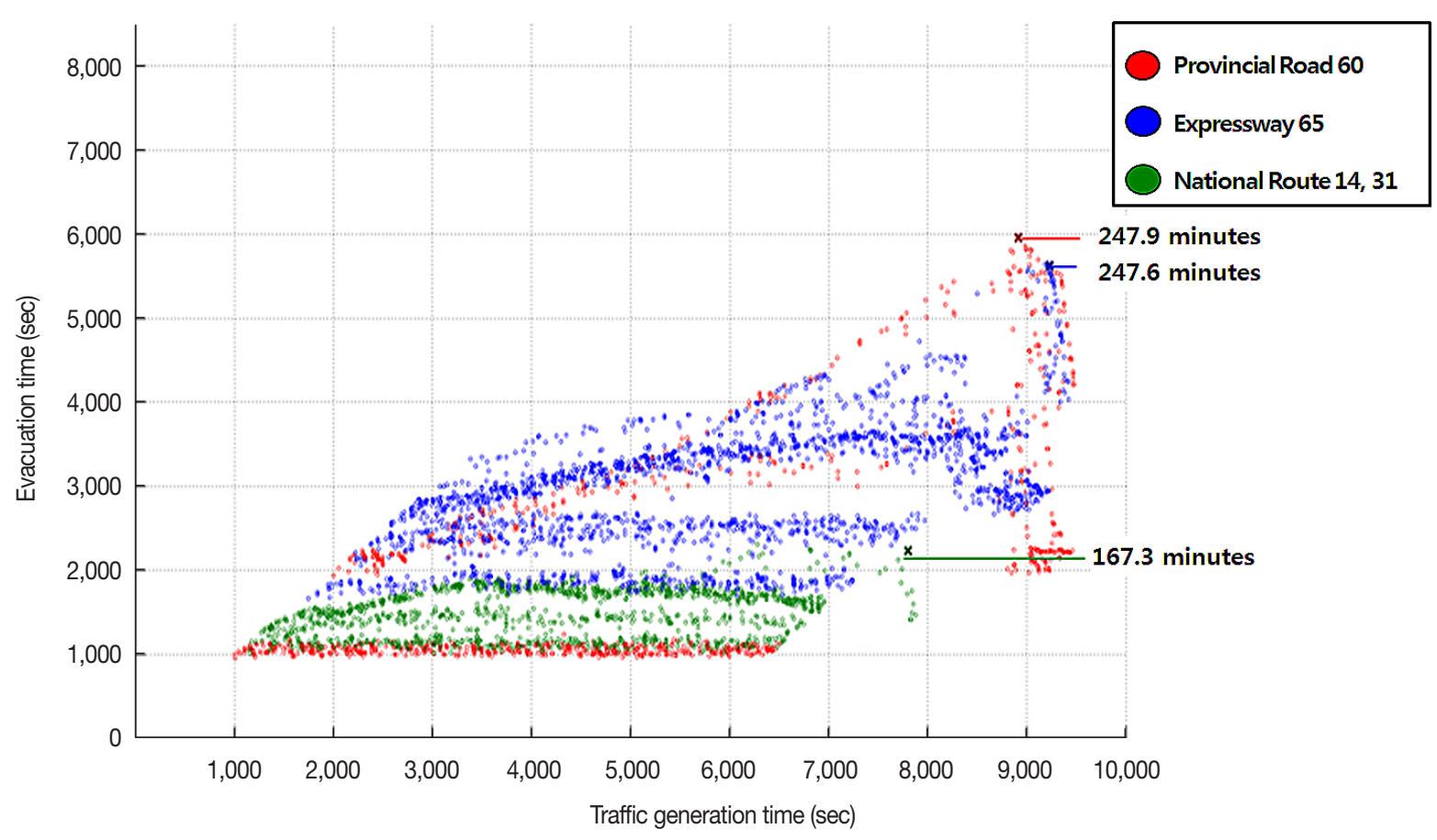

Fig. 7. Estimated 21-km evacuation time by vehicle for each exit route from the Kori site. 


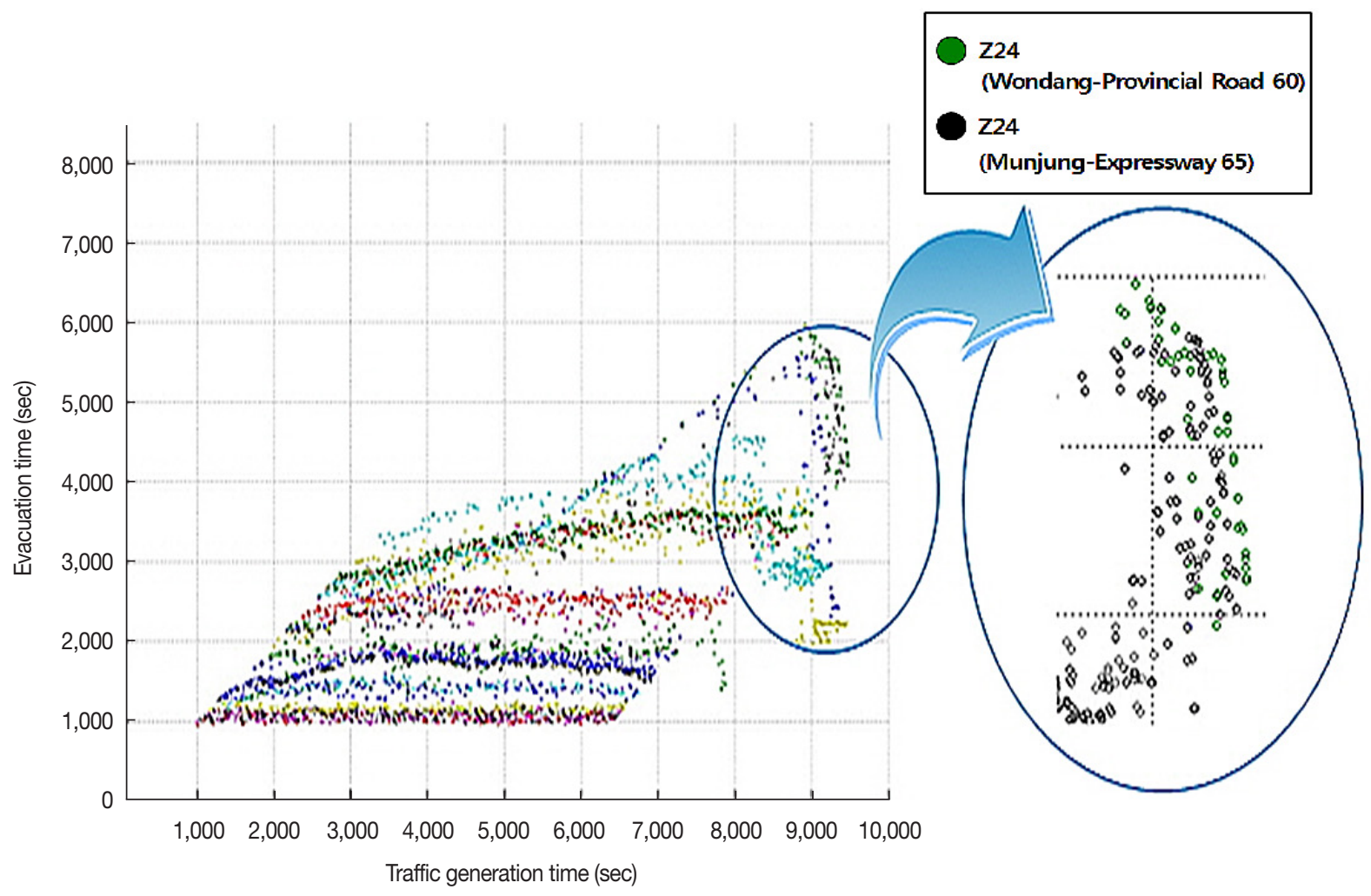

Fig. 8. Bottleneck sections within $21 \mathrm{~km}$ from the Kori nuclear site for each origin-destination (O-D) pair.

diation through an evaluation of the expected exposure dose. We found that the total evacuation time may be delayed by 30 to 90 minutes after the fallout arrival time at the PAZ boundary, and by 112 to 158 minutes at the UPZ boundary. In particular, assuming that a shadow evacuation of $20 \%$ or more occurs at the boundary of the PAZ, a delay in the evacuation due to traffic jams is expected, which would lead to approximately $10 \mathrm{mSv} \cdot \mathrm{h}^{-1}$ (or higher) radiation exposure at the boundary of the nuclear power plant site and approximately 4-6 $\mathrm{mSv} \cdot \mathrm{h}^{-1}$ of radiation exposure at the boundary of the PAZ.

The evacuation time estimates presented in the radiological emergency plans for Shin Kori-3 and 4, approved by the NSSC in February 2013, do not differ greatly from the values we obtained in the current study, as they found a preparation time of 60-120 minutes and evacuation travel times of 73-178 minutes, despite differences in the software modules that were used, the spatial range, the evacuee types, and the survey method. Therefore, the calculated resident evacuation times in the radiological emergency plans for Shin Kori3 and 4 may be considered conservative. Moreover, the public evacuation time is expected to decrease further when the planned roadway network opens and the recommendations of this study are put into practice.
In order to minimize deterministic effects on the residents in the PAZ, the following measures must be implemented: the current decision-making process should be made simpler, each organization should set time objectives for emergency responses, resources (both human and material) for resident protection should be secured before an emergency, and maintenance of such resources should be regularly monitored in order to shorten the evacuation preparation time.

In addition, educational outreach programs such as those provided by the Korea Academy of Nuclear Safety should be offered to the public, schools, hospitals, and nursing homes. People should be encouraged to participate in emergency drills to familiarize themselves with the actions that need to be taken in emergencies. People vulnerable to disasters, such as pregnant women, the elderly, and patients who may require longer evacuation preparation and whose condition may worsen during the long hours of transport, should be the first to be evacuated, before the declaration of a code-red emergency; Additionally, facilities such as hospitals and nursing homes outside the UPZ need to be designated in advance and included in the emergency plan.

In case of a code-red emergency, thyroid protective agents should be distributed to the residents in the PAZ for them to 
take immediately. In addition, close cooperation between the emergency headquarters and on-site responders is crucial for insuring a timely response. Phased protection action plans for each street and administrative unit should be established, so that traffic congestion does not occur in the UPZ due to shadow evacuation.

For future research, simulations of shadow evacuation in the neighboring Ulju-gun area and the UPZ should be further increased from $20 \%$ to $100 \%$. In addition, the effects of a range of evacuation vehicles, such as trains, ships, and soonto-be-opened road networks should be considered.

\section{References}

1. International Atomic Energy Agency. Preparedness and response for a nuclear or radiological emergency. IAEA safety standards series No. GS-R-2. 2002;27-44.

2. International Atomic Energy Agency. Arrangements for preparedness for a nuclear or radiological emergency. IAEA safety standards series No. GS-G-2.1. 2007;89-99.
3. International Atomic Energy Agency. Actions to protect the public in an emergency due to severe conditions at a light water reactor. EPR-NPP Public Protective Actions. 2013;102-114.

4. Nuclear Safety and Security Commission. Act on measures for the protection of nuclear facilities, etc. and prevention of radiation disasters. Article 20-2 (Establishment, etc. of Radiation Emergency Planning Zones). 2014;34-35.

5. U.S. Nuclear Regulatory Commission. Criteria for preparation and evaluation of radiological emergency response plans and preparedness in support of nuclear power plants. Appendix 1 to 4. NUREG-0654/FEMA REP 1, Rev. 1. 1980;1.1-4.1.

6. U.S. Nuclear Regulatory Commission. Criteria for development of evacuation time estimate studies. NUREG/CR-7002. 2011;137.

7. International Atomic Energy Agency. Actions. Method for developing arrangements for response to a nuclear or radiological emergency. EPR-METHOD. 2003;2-14.

8. Nuclear Regulation Authority. Nuclear emergency response guidance. 2012;3-18.

9. Korea Hydro \& Nuclear Power Co. Ltd. Shin Kori Unit 3 and 4 radiation emergency plan. 2013;261-267. 